level of information given $(76.5 \%)$, there remained a substantial minority who were not.

Conclusion The number of patients attending the PAU varied across days of the week and times of day. Attention needs to be given to staffing PAUs between 17:00-22:00 hours as this is the busiest time with much reduced staffing usually. On the whole, parents were satisfied with their experience within the PAU. However, the length of stay of patients in the PAU needs to be reduced without harming the quality of patient care. A substantial minority were not satisfied with the level of information they received. This may be attributed to pressure of time on staff.

\section{G145(P) DELPEDS: A TOOL TO IMPROVE THE PATIENT EXPERIENCE OF THE CLINICIAN'S WARD ROUNDS}

doi:10.1136/archdischild-2013-304107.157

${ }^{1} \mathrm{R}$ Puttha, ${ }^{2} \mathrm{R}$ Thalava. ${ }^{1}$ Paediatrics, University Hospitals of South Manchester, Manchester, UK: ${ }^{2}$ Orthopaedics, Tameside General Hospital NHS Foundation Trust, Manchester, UK

Aim Hospital admission can be a stressful time for most patients and parents. The aim of introducing this tool is to improve the parent and patient experience of the medical consultation and benefit maximum from the clinicians ward rounds.

Methods We designed a tool considering the common parameters a parent would like to know when their child is admitted as an inpatient (DELPEDS). We studied the validity of the tool over two of the first author's hot weeks. Parents were handed over the tool sheet at the time of admission to the ward so that they had enough time to read, think and add anything else they would like to know during the ward round.

Results Out of the 30 patients who were provided with the tool 22 patients gave feedback. All the 22 parents found it very helpful and there were positive comments that the tool helped them think various aspects of their child care and ask questions so that they had a clear understanding of their child's health, basic needs and probable discharge. For the clinician, it guided in having a structure and improves the consultation focusing on patient/parent need especially in a busy winter ward round.

Conclusion DELPEDS, provided clinician with a structured tool, guidance to parents regarding how they can benefit from medical consultations and seems to have improved patient experience of the ward rounds.

\section{G146(P) THE IMPACT OF TEAMWORK AND PRACTICAL SKILLS TRAINING IN OBSTETRIC EMERGENCIES AND NEONATAL RESUSCITATION AT A TERTIARY HOSPITAL IN ETHIOPIA}

doi:10.1136/archdischild-2013-304107.158

T D Chawatama, S Philip. Paediatrics and Obstetrics, Ayder Hospital, Mekelle, Ethiopia

Aims To evaluate the effect on the stillbirth rate at a tertiary institution in a low-resource setting through the development of a multi-disciplinary training programme using local trainers.

Methods Twenty-one senior staff (anaesthetists, midwives, doctors, nurses and educators) completed a three day "training of trainers" course in the multi-disciplinary management of obstetric emergencies and neonatal resuscitation. These trainers then delivered six courses (each over two days) to 138 staff \& postgraduate students actively involved in the care of labouring mothers and neonates. The course material was derived from the Ethiopian Federal Ministry of Health, World Health Organisation and Ethiopian Paediatric Society's guidelines.

Results The stillbirth rate over three months following the completion of the training project was compared with the rate in the three month period preceding the initial "training of trainers" course. The mean stillbirth rate fell from $7.6 \%$ (SD 2.1\%) to 5.3\% (SD 1.1\%). However, this reduction was not statistically significant $(p=0.08)$.
A pre-course and post-course (true/false) test was used to assess the participant's knowledge. The average test scores increased from $65 \%$ (pre-test) to $85 \%$ (post-test.)

Anonymysied feedback was collected to review the participants views and acceptablity of using local trainers. $97 \%$ of respondents felt they had learnt something new. In addition, most respondents found local trainers to be acceptable and credible.

Conclusion The introduction of multi-disciplinary training in obstetric emergencies and neonatal resuscitation using local trainers brough about objective and subjective improvement in staff knowledge and may have contributed to a reduced stillbirth rate. Furthermore, a 'train the trainers' model has provided a potentially sustainable resource in the hospital which should continue to impact maternal and perinatal morbidity and mortality. However, further assesment of the impact is required and improvements in other aspects of the health service (such as regular audit and multidisciplinary review of cases of mortality) are recommended.

\section{G147(P) EVALUATING THE IMPACT OF INTRODUCING ADVANCED PAEDIATRIC LIFE SUPPORT TRAINING IN A TEACHING HOSPITAL IN ZAMBIA}

doi:10.1136/archdischild-2013-304107.159

${ }^{1} \mathrm{P}$ Tyndall, ${ }^{2} \mathrm{E}$ Seddon, ${ }^{3} \mathrm{~S}$ Wa Somwe, ${ }^{4} \mathrm{P}$ Seddon. ${ }^{1}$ GlobalHealth, Brighton \& Sussex Medical School, Brighton, UK; ${ }^{2}$ Brighton-Lusaka Link Project, Brighton \& Sussex University Hospitals NHS Trust, Brighton, UK; ${ }^{3}$ Child Health, University Teaching Hospital, Lusaka, Zambia; 'Royal Alexandra Children's Hospital, Brighton \& Sussex University Hospitals NHS Trust, Brighton, UK

Aims The effective treatment of acutely sick children in resourcepoor settings (including teaching hospitals in most developing countries) is limited by resources, but also by knowledge, skills and attitudes. Introducing rigorously-assessed, multidisciplinary training in paediatric life support may help address these issues, but there is limited evidence of the effectiveness of this approach.

As part of a Zambia-UK Health Link, we carried out a needs assessment at the Zambian partner's paediatric unit, which demonstrated that (a) most deaths were occurring within 48 hours of admission, and (b) staff expressed lack of confidence in dealing with acutely sick children. After assessing the options, we collaborated to establish Advanced Paediatric Life Support (APLS) training in Zambia.

Methods We assessed the impact of the APLS programme in 3 ways: (a) by semi-structured interviews with trainees, to assess the perceived relevance and impact of the training, with a mixture of free-form and 5-point Likert responses (b) by comparing mortality figures, from hospital records, before and after APLS training commenced in 2011 (c) by examining changes in clinical practise from a sample of case records (vital signs/emergency treatment recorded), after APLS training commenced.

Results In answer to "How relevant was the course to your everyday practise?", median response was 5 "Very relevant" - range 3-5; for "Will doing this course change how you practise?", median (range) response was 5 "A lot" (3-5).

Total mortality following admission decreased from 691 (15\% of admissions) during Oct-Dec 2010 to 530 (12\%) during Oct-Dec 2011 ( $p<0.001)$. Deaths on the day of admission also decreased, from $149(3.2 \%)$ to $102(2.3 \%)$ respectively $(p<0.01)$. The proportion of patients with vital signs and initial management recorded showed a trend to increase from 2010 to 2011, though this was only significant for recording of heart rate.

Conclusion APLS training is perceived as relevant to their needs by healthcare staff in a Zambian tertiary paediatric unit, and has been associated with evidence of improved management and reduced inhospital mortality. Further work is needed to establish whether the improvements were due to the training, and whether they are sustainable. 